\title{
Comparative studies in oddity learning: III. Apparatus transfer in chimpanzees and children'
}

\author{
PASCHAL N. STRONG, JR. \\ TEXAS TECHNOLOGICAL COLLEGE
}

Three adolescent chimpanzees and 26 children from 3 to 6 years of age were trained on one-trial, two-position oddity to a criterion on two consecutive days at $90 \%$ or better. They were then transferred to a different apparatus presenting the same oddity problems. Both chimpanzees and children gave evidence of apparatus transfer.

Previous work by Strong (1965) has shown that monkeys show no evidence of transfer of oddity learning when, after attaining criterion on one-choice, twoposition oddity problems, they are transferred to a new apparatus presenting the identical problems. Since Strong \& Hedges (1966) and Strong (1966) have demonstrated a systematic increment in the ability of chimpanzees and children to learn oddity, it was decided to see if these subjects show better ability for apparatus transfer than rhesus monkeys.

Subjects

Ss were three adolescent chimpanzees who had previously learned simple one-trial, two-position oddity in a modified WGTA as described by Strong \& Hedges (1966), and 26 children who had previously learned the same problems on either a WGTA or Primate Automatic Testing Apparatus-key (PATA-K) previously described by Strong (1966) and modified to be portable.

\section{Procedure}

After Ss had learned oddity on the original apparatus, they were pretrained on the new apparatus in the same manner as with the original apparatus and then presented with the same one-trial, two-position oddity problems as in the original training. Criterion was two days at $90 \%$ or better correct. Forty-eight problems were presented each day.

\section{Results}

Table 1 shows the original and transfer apparatus learning and clearly indicates that transfer did take place. All chimpanzees showed large savings scores $(33 \%, 60 \%$, and $80 \%$ ) and 10 of the 13 children who took more than the two criterion days to learn the oddity problem showed positive transfer. If a $S$ learned the original problem in two days, as did 13 of the 26 , then there was no possibility for a positive transfer score to occur although one of these children did show a $50 \%$ increase in trials to criterion on transfer.

\section{Discussion}

Because of a shortage of naive chimpanzees, we were unable to test transfer from PATA-K to WGTA. This

\begin{tabular}{|c|c|c|c|c|c|c|}
\hline Group & $N$ & $\begin{array}{l}\text { Original } \\
\text { Appo- } \\
\text { ratus }\end{array}$ & $\begin{array}{l}\bar{X} \text { Trials } \\
\text { to cri- } \\
\text { terion }\end{array}$ & $\begin{array}{l}\text { Transfer } \\
\text { Appa- } \\
\text { ratus }\end{array}$ & $\begin{array}{l}\bar{X} \text { Trial } \\
\text { to cri- } \\
\text { terion }\end{array}$ & $\begin{array}{c}\text { X Savings } \\
\text { Score }\end{array}$ \\
\hline $\begin{array}{l}\text { Chimpanzees } \\
\text { Children }\end{array}$ & & WGTA & 2208.0 & PATA-K & 944.0 & $+57 \%$ \\
\hline 3 yr. & 1 & WGTA & 480.0 & PATA-K & 144.0 & $+70 \%$ \\
\hline 4 yr. & 5 & WGTA & 297.6 & PATA-K & 288.0 & $+3 \%$ \\
\hline 5 yr. & 9 & WGTA & 314.6 & OATA-K & 213.3 & $+32 \%$ \\
\hline 5 yr. & 4 & PATA-K & 504.0 & WGTA & 168.0 & $+67 \%$ \\
\hline $6 \mathrm{yr}$. & 2 & WGTA & 96.0 & PATA-K & 96.0 & $--^{*}$ \\
\hline $6 \mathrm{yr}$. & 5 & PATA-K & 172.8 & WGTA & 96.0 & $+44 \%$ \\
\hline
\end{tabular}

* 96 trials is the minimum score a subject can make and thus no positive transfer is possible.

was also true for the three and four year old children since only one of twelve children in this age group learned oddity on the PATA-K and this child was not available for transfer testing. It is interesting to note that six children in the 3-4 yedr old range who learned on the WGTA all learned on the PATA-K and five of six showed positive transfer.

It would appear that apparatus transfer is a meaningful dimension for comparative studies and seems to differentiate the anthropoid apes, as represented by the chimpanzees, from lower primates. Although the $\mathrm{N}$ is small for the chimpanzees it is of interest to note that no chimpanzee showed perfect transfer whereas $6 / 13$ children who showed gradual learning on the original apparatus transferred perfectly to the new apparatus. Future testing on chimpanzees may indicate that they are unable to show perfect transfer.

\section{References}

Strong, P. N. Learning and transfer of oddity as a function of apparatus and trials per problem. Psychon. Sci., 1965, 3, 19-20.

Strong, P. N., \& Hedges, R. M. Comparative studies in simple oddity learning: I cats, raccoons, monkeys, and chimpanzees. Psychon. Sci., 1966, 5, 3-14.

Strong, $\mathbf{P}$. N. Comparative studies in simple oddity learning: II children, adults, and seniles. Psychon. Sci., 1966, 6, 459-460.

\section{Notes}

1. This work was supported under Air Force Contract No. 29 (600)2939. Grateful acknowledgement is made to the comparative Psychology Laboratory personnel at Hallaman AFB for their cooperation and encouragement.

2. Now at the University of South Florida. 